\title{
電気抵抗法を用いた耐候性鋼の腐食挙動評価
}

\author{
面田真孝 ${ }^{1) *}$ ，水野大輔 ${ }^{1)}$ ，三浦進一 ${ }^{2)}$ ，石川信行 ${ }^{1}$ \\ 1) JFE スチール株式会社 スチール研究所(京浜) \\ 2) JFE スチール株式会社 スチール研究所(倉敷)
}

\section{Corrosion Behavior Investigation of Weathering Steel by Using Electrical Resistance Technique}

\author{
Masataka Omoda $^{1 *}$, Daisuke Mizuno ${ }^{1)}$, Shinichi Miura ${ }^{2)}$ and Nobuyuki Ishikawa ${ }^{1)}$ \\ 1) Steel Research Laboratory, JFE Steel Corporation (Keihin) \\ 2) Steel Research Laboratory, JFE Steel Corporation (Kurashiki)
}
*責任著者(Corresponding Author) ＝210-0855 川崎市川崎区南渡田町 1-1(1-1 Minamiwatarida-cho, Kawasaki-ku, Kawasaki, 210-0855, Japan)
E-mail: m-omoda@jfe-steel.co.jp

\begin{abstract}
It is important to understand the relation between changeable environmental condition and corrosion behavior of each weathering steel for maintenance management of weathering steel structures. For this subject, it is thought that corrosion monitoring by using the electrical resistance technique is the most suitable. In this study, corrosion behavior in ISO16539 Method B that simulates atmospheric corrosion environment and actual use environment was measured. The difference of corrosion behavior among weathering steels could be clearly measured by the unit $\mu \mathrm{m}$ both in laboratory test and exposure test. However, in only high salinity environment, the output corrosion loss of sensor was larger than actual corrosion loss by increasing the partial electrical resistance caused by large roughness due to locally corrosion on the sensor. And applicable salinity environment for this sensor was decided up to 1 mdd of airborne sea salt. Thus, by using the electrical resistance technique, the difference of corrosion behavior of each weathering steel can be measured, furthermore, it has possibility that environmental condition in which weathering steels show significant corrosion resistance might be clarified by comparing with environmental factors.
\end{abstract}

Key words : electrical resistance technique, weathering steel, ISO16539 Method B, exposure test

\section{1. 緒}

$\overline{\overline{\bar{⿳}}}$

日本国内における耐候性鋼橋梁の受注件数および使用 された鋼材の重量は, 2000 年頃を境に減少しており, 2012 年度の時点では, ピーク時の約半分となっているも のの, 2015 年時点では，全国に約 190 万 ton の耐候性橋 梁が架かっている ${ }^{1)}$ ．これらの耐候性鋼橋梁を保守・管 理していく上で，日々変化する腐食環境と各種耐候性鋼 の腐食挙動の関係を把握することが重要となる。これに は，腐食量の経時変化を詳細に計測可能な腐食モニタリ ングする技術が有効である ${ }^{2-5)}$ 。本研究では, 腐食減肉 による電気抵抗の増加を腐食量に換算する電気抵抗法を 用いた腐食センサ (以降 ER センサ) に耐候性鋼を適用 し, 大気腐食試験環境を模擬した耐食性試験法 ISO16539B 法 ${ }^{6)}$ と大気暴露環境で腐食モニタリングを行 い，各種耐候性鋼の腐食挙動の差を検討した結果を報告 する.

\section{2. 実 験 方 法}

\section{1 供試材}

ER ンサとして，French Corrosion Institute 製の AirCorr- $\mathrm{O}^{7)}$ を用いた。本 ER センサは, 防水仕様のた
め, 屋外大気腐食環境での使用が可能である.さらに, 内蔵リチウムイオン電池駆動により，2３年間の連続測 定も可能である. ER センサは計測部と樹脂により防食 された参照部で構成されており, 参照部の電気抵抗值を 基準とした測定部の電気抵抗変化から, 以下の (1) 式で 腐食量が算出される.

$$
C D=t_{\text {init }}\left(\frac{R_{\text {ref, init }}}{R_{\text {sens, init }}}-\frac{R_{\text {ref }}}{R_{\text {sens }}}\right)
$$

ここで, $C D[\mu \mathrm{m}]$ は腐食量, $t_{i n i t}[\mu \mathrm{m}]$ はセンサの初期厚 さ, $R_{\text {ref, init }}[\Omega]$ は参照部の初期抵抗值, $R_{\text {sens, init }}[\Omega]$ は計測 部の初期抵抗值, $R_{\text {ref }}[\Omega]$ は記録時の参照部の抵抗值, お よび $R_{\text {sens }}[\Omega]$ は記録時の計測部の抵抗值である. Table 1 に示す 4 種類の鋼材, JIS 普通鋼 SM, JIS 耐候性鋼 $\mathrm{SMA}$ ，主に $\mathrm{Ni}$ を多く添加(1〜3\%) して耐塩分特性を高 めた $\mathrm{Ni}$ 系高耐候性鋼 Type1, Type2 を厚さ $250 \mu \mathrm{m}$ に 加工したセンサを用いた。測定間隔はラボ試験を 1 分, 暴露試験を 10 分とした。 また比較として, 各鋼種を $150 \times 70 \times 3 \mathrm{~mm}$ に機械加工し, 表面を\#120のグライン ダー処理した試験片を同時に暴露試験に供した。腐食試 験片は端面と裏面をマスキングテープで保護した。暴露 試験終了後の腐食試験片は, JIS Z 2371 8 に規定された塩 酸 $500 \mathrm{ml}$, ヘキサメチレンテトラミン $3.5 \mathrm{~g}$ に蒸留水を 加え， $1,000 \mathrm{ml}$ にメスアップした酸洗液を用いて腐食生 成物のみ除去し, 初期重量と酸洗後の重量との差から腐 食量を算出した。 
Table 1 Chemical composition of test specimens (mass\%)

\begin{tabular}{|c|c|c|c|c|c|c|c|c|c|}
\hline Type & $\mathrm{C}$ & $\mathrm{Si}$ & $\mathrm{Mn}$ & $\mathrm{P}$ & $\mathrm{S}$ & $\mathrm{Al}$ & $\mathrm{N}$ & $\mathrm{O}$ & Others \\
\hline \hline SM & 0.094 & 0.19 & 0.69 & 0.018 & 0.0038 & 0.028 & 0.0026 & 0.0022 & \\
\hline SMA & 0.098 & 0.20 & 0.69 & 0.020 & 0.0034 & 0.029 & 0.0037 & 0.0019 & $\mathrm{Cu}, \mathrm{Ni}, \mathrm{Cr}$ \\
\hline Type1 & 0.089 & 0.19 & 0.73 & 0.021 & 0.0042 & 0.024 & 0.0020 & 0.0016 & $\mathrm{Ni}, \mathrm{Mo}$ \\
\hline Type2 & 0.092 & 0.20 & 0.74 & 0.022 & 0.0039 & 0.020 & 0.0025 & 0.0024 & $\mathrm{Cu}, \mathrm{Ni}$ \\
\hline
\end{tabular}

\section{2 ラボ腐食試験}

Fig. 1 に示す ISO16539B 法 $\left(60^{\circ} \mathrm{C}, 35 \% \mathrm{RH}, 3 \mathrm{~h} \Leftrightarrow 40^{\circ} \mathrm{C}\right.$, $95 \% \mathrm{RH}, 3 \mathrm{~h} /$ 遷移時間 $1 \mathrm{~h})^{5)}$ を実施した。塩分付着工程 の付着塩分量を $1,000 \mathrm{mg} \cdot \mathrm{m}^{-2}$ に制御して試験を行った。 試験期間を 28 日間とした。温湿度は，日立アプライア ンス (株) 製 恒温恒湿器 EC-26HHPにより制御した。付 着塩分として，八洲薬品株式会社製金属腐食試験用アク アマリンを用いた。塩分はエアブラシを用いた噴霧方法 により付着させ, 付着量は人工海水の濃度と噴霧前後の ERセンサの重量変化によって制御した.

\section{3 屋外大気暴露試験}

大気暴露試験は，沖縄暴露試験場(沖縄県うるま市)／ 離岸距離 $100 \mathrm{~m}$ と川崎暴露試験場(神奈川県川崎市) /離 岸距離 $600 \mathrm{~m}$ の軒下環境で行った。設置方法は橋梁を想 定して，水平天向きとした，各種 $\mathrm{ER}$ センサおよび腐食 試験片は，水平天向きの軒下で暴露試験を行った。試験 期間は，沖縄暴露試験場では 2015 年 6 月 27 日から 2016 年 2 月 1 日, 川崎暴露試験場では 2015 年 8 月 11 日から 2017 年 10 月 27 日とした。また, 同時に気温, 湿度抢よ び飛来塩分量の計測を行った。温湿度計測は, 日置電機 (株) 製 LR5001 を用いた。飛来塩分量は JIS Z 2382 に規 定されたドライガーゼ法を用いて計測を行った．センサ の測定間隔は 10 分とし, 飛来塩分量測定は 1 か月ごと とした.

\section{3. 実 験 結 果}

\section{1 ラボ腐食促進試験}

各種供試鋼の ER センサを付着塩分量 $1,000 \mathrm{mg} \cdot \mathrm{m}^{-2}$ の ISO16539B 法の試験に供した結果を Fig. 2 に示す．JIS 耐候性鋼／SMA については，7〜14 日の期間において計 測機器不良のためにデー夕が取得できなかった，腐食モ ニタリングの結果は，一般的な大気腐食環境に打ける耐 食性の序列(悪)SM, SMA, Type1, Type2(良) $)^{9)}$ となっ ており，さらには出力が同時に試験に供した試験片の腐 食量と打拈よそ一致したことから，電気抵抗法を用いる ことで各種耐候性鋼の経時変化を詳細に評価することが 可能となった。ここで $3 \sim 4$ 日ごとに現れているスパイ クは, 水洗過程における急激な温度変化による電気抵抗 值変化を補正しきれなかったものである。また 1 日間の 腐食モニタリングの出力を抽出した結果を Fig. 3 に示 す。乾燥過程において供試鋼の腐食は停止し，湿潤過程 において腐食は進行した，本試験条件においては，湿潤過 程抢ける各種供試鋼の腐食速度の差が明確に認められた。

\section{2 大気暴露試験}

\subsection{1 大気暴露試験場の環境}

沖縄抢よび川崎暴露試験場の 2015 年 6 月から 2016 年

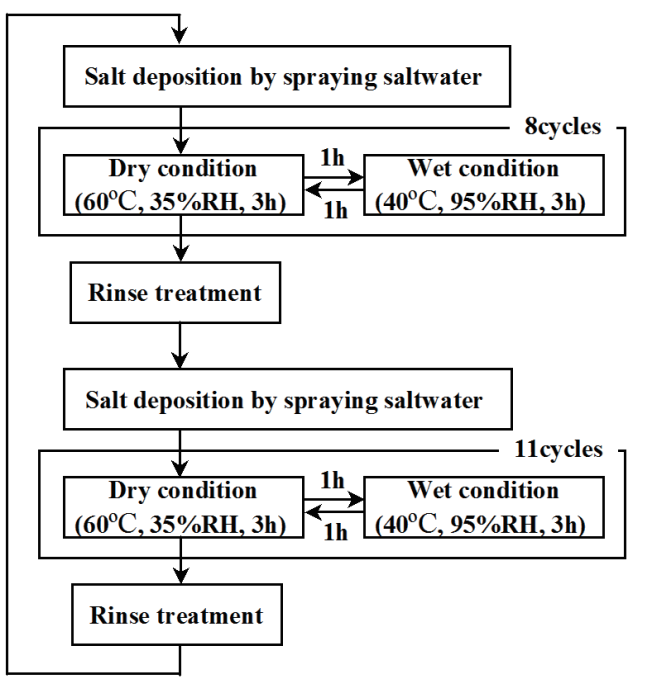

Fig. 1 Test condition of ISO16539 Method B.

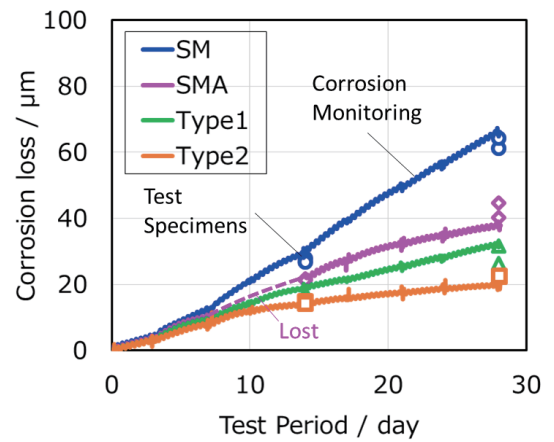

Fig. 2 Corrosion monitoring result of each kind of weathering steel in ISO16539 Method B.

5 月までの 1 年間の月ごとの温度，相対湿度および飛来 塩分量を Fig. 4 に示す。沖縄の腐食環境は，年平均で気 温 $24.0^{\circ} \mathrm{C}$, 相対湿度 $80.0 \%, \mathrm{NaCl}$ 換算の飛来塩分量 $0.603 \mathrm{mdd}$ と高温多湿かつ塩分も耐候性鋼の適用可能基準 である $\geqq 0.05 \mathrm{mdd}$ の約 10 倍と非常に厳しい腐食環境で あった。一方で, 川崎の腐食環境は, 年平均で気温 $17.5^{\circ} \mathrm{C}$, 相対湿度 $70.3 \%, \mathrm{NaCl}$ 換算の飛来塩分量 $0.063 \mathrm{mdd}$ と 比較的マイルドな腐食環境であった。また，川崎は関東 平野に位置しており, 冬場の平均湿度が $60 \%$ 前後と低い ことが特徴である.

\subsection{2 沖縄暴露試験}

沖縄暴露試験場における腐食モニタリング結果を Fig. 5 に示す、鋼種ごとの腐食挙動の違いがモニタリングされ ているとともに, 台風のときに腐食速度が増加し, 陸風 のときに腐食速度が低下した。これは，台風時には塩分 量が増加かつ湿った空気がもたらされ，陸風時は，塩分 が脱落したためと考えられる。一方で, 試験片の腐食量 

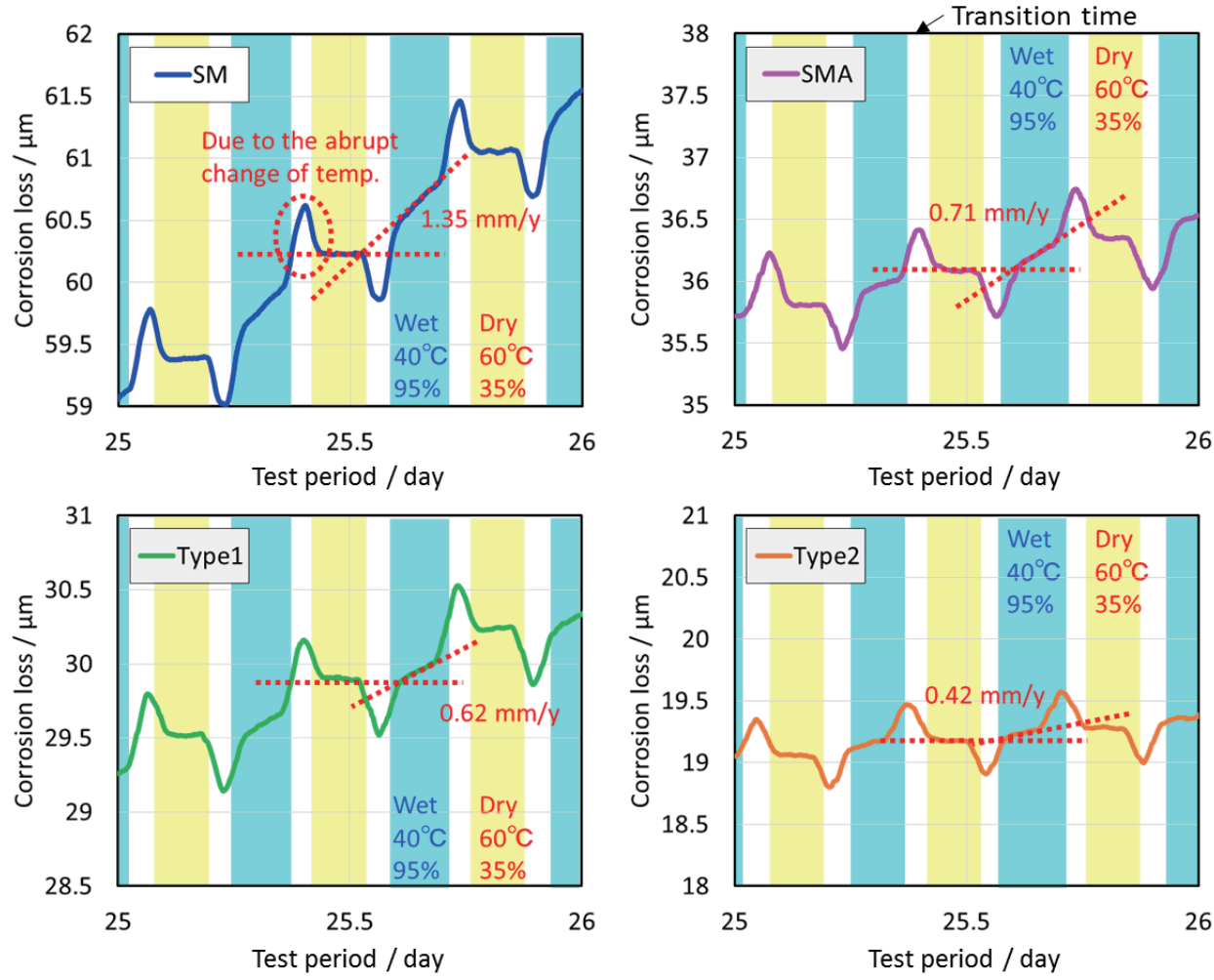

Fig. 3 Enlarged parts of corrosion monitoring result of each kind of weathering steel in ISO16539 Method B.

a)

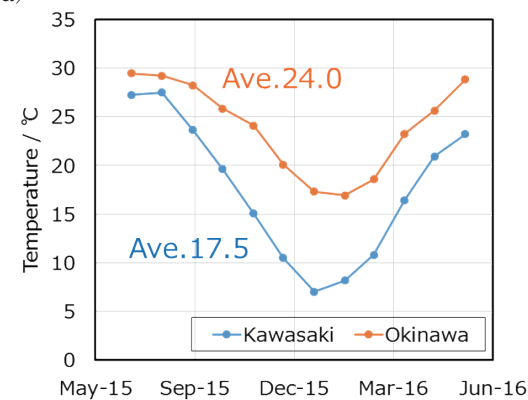

b)

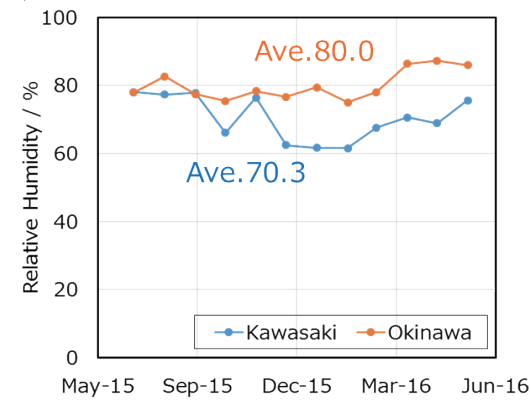

c)

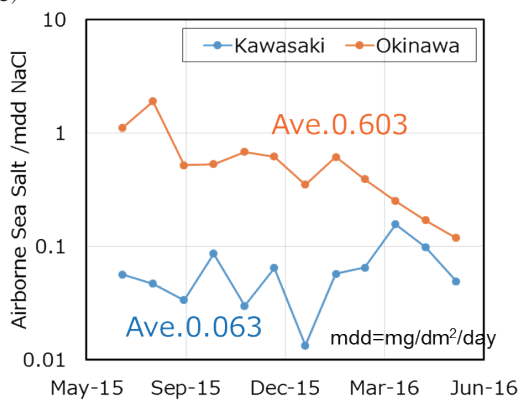

Fig. 4 Change of environment in Okinawa and Kawasaki exposure test site through a year. a) Temperature, b) Relative Humidity, and c) Airborne Sea Salt.

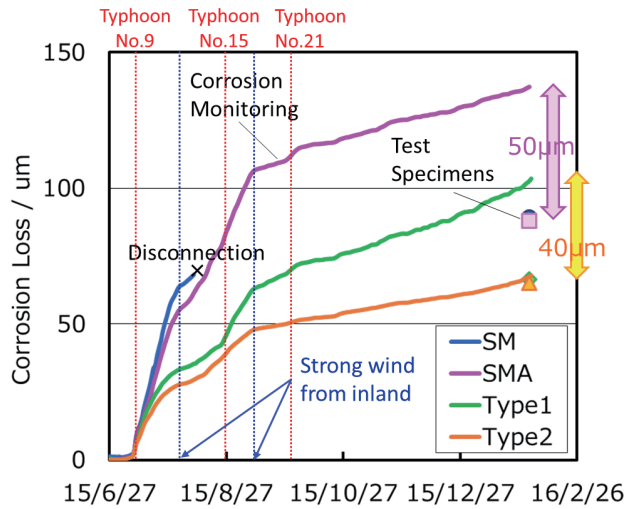

Fig. 5 Corrosion monitoring results of weathering steels in Okinawa exposure test site.
を比較するもっとも耐食性の良い Type2 を除いて ER セ ンサ出力が試験片の腐食量より大きい結果となった。

\subsection{3 川崎暴露試験}

川崎暴露試験場における腐食モニタリング結果を Fig. 6 に示す。川崎は比較的マイルドな腐食環境であるため, もっとも耐食性の高い $\mathrm{Ni}$ 系耐候性鋼／Type2 の腐食モ ニタリングは実施しなかった。腐食モニタリング結果か ら，鋼種ごとの腐食挙動の違い，低温かつ乾燥する冬場 の腐食速度の低下が観測できたとともに，ER センサ出 力から計算される腐食量は, 試験片の腐食量に近い值と なった。

\section{4. 考察}

4.1 大気暴露試験と ISO16539 B 法の腐食挙動の比較 ISO16539 B 法は，人工海水を試料表面に均一に噴霧 
付着させることで実環境の結露状態を再現した工程と, 乾燥・湿潤のサイクルを実環境と同様の絶対湿度一定と する工程を組み合わせることを特徵とする大気腐食環境 の再現試験方法である。今回は, 腐食モニタリング結果 から得られる腐食挙動の観点から再現性の評価を行っ た. Fig. 7 にJIS 炭素鋼 $/ \mathrm{SM}$ に対する沖縄暴露試験場に おける 1 日分の腐食モニタリング結果と ISO16539 B 法 の実環境 1 日分に相当する腐食モニタリング結果を示 す。また，比較のために併せて温湿度変化も示す。実環 境における日中の乾燥過程における腐食の停止, 夜間の 湿潤過程における腐食の進行を ISO16539 B 法のサイク ルにより再現されていることが分かる．加えて，相対湿 度が約 $60 \%$ を下回ると腐食が停止することが双方の腐食 モニタリング結果から分かった．以上のことから，腐食 量の経時変化の観点からも ISO16539 B 法は大気腐食環 境を再現した試験法と言える。

\section{2 センサ適用可能環境}

3.2.2の結果において, 沖縄暴露試験場における試験片と $\mathrm{ER}$ センサの腐食量の大きな乘離が認められた。この原因 を解明するために, 今までの炭素鋼の腐食モニタリング結

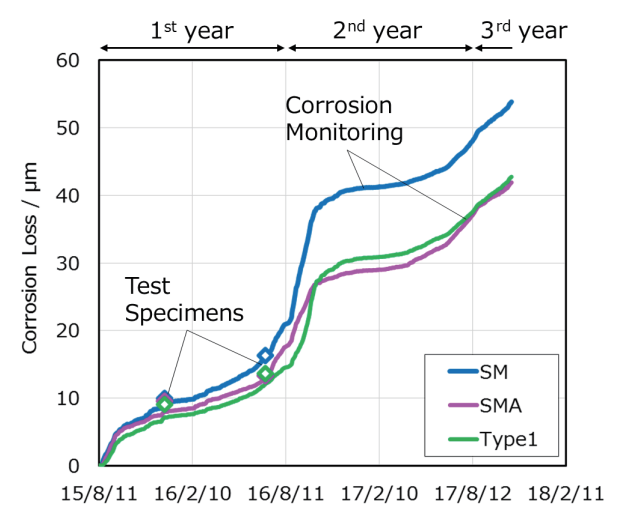

Fig. 6 Corrosion monitoring results of weathering steels in Kawasaki exposure test site.

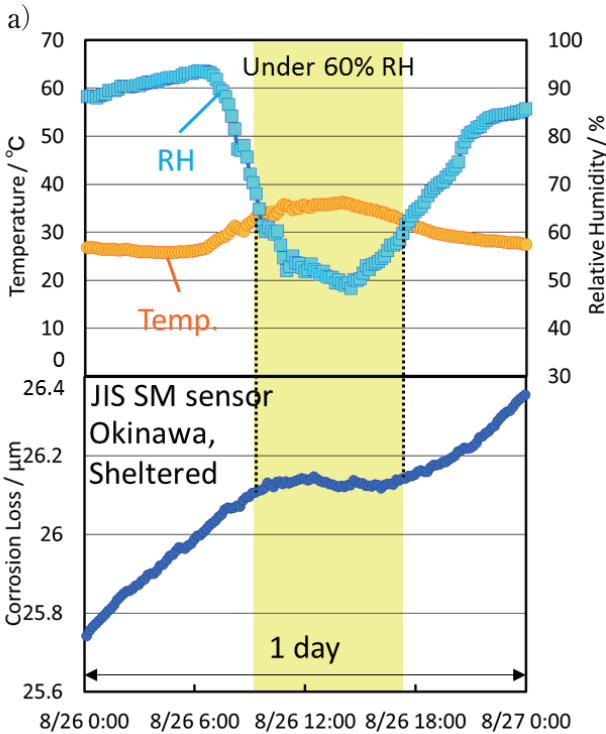

果に対して, 各領域の飛来塩分量における $\mathrm{ER}$ センサと試 験片の腐食量を比較した結果を Fig. 8 に示す. 飛来塩分量 が $1 \mathrm{mdd} \mathrm{NaCl}$ を超える環境で腐食モニタリングを行った 場合，いくつかの ER センサと試験片の腐食量に乘離が 発生した。酸洗によるさび除去により残存した ER セン サ形状を見ると, Fig. 8 中の写真に示すように, 高塩分 の影響により ER センサ部分に虫食い状の不均一な腐食 が発生していることが分かった．このことから，乘離は 部分的な電気抵抗が非常に大きくなったことに起因する と考えられる.

以上から，ERセンサ適用可能範囲の飛来塩分量は $1 \mathrm{mdd} \mathrm{NaCl}$ 以上の環境に曝されない地域であるが, ま た一般的に耐候性鋼が適用可能な地域は $0.05 \mathrm{mdd} \mathrm{NaCl}$ 以下であり，本 ER センサを用いた耐候性鋼の評価の実 用化には問題はないと考えられる。

\subsection{JIS 耐候性鋼の腐食速度の日ごとの変化}

JIS 耐候性鋼／SMAの耐食性の経時変化を評価するた めに, JIS 普通鋼／SM に対して日ごとの腐食速度を比 較した. Fig. 9 に暴露開始 1 年目と 2 年目の比較結果を 示す. 夏場から開始した 1 年目の初期 1 か月程度は普通 鋼, 耐候性鋼ともに $0.04 \sim 0.1 \mathrm{~mm} \cdot \mathrm{y}^{-1}$ 程度の腐食速度の 速い日が多く, その差も確認されなかった。一方で, 1 年目の終盤の夏場に腐食速度が速い日には, 炭素鋼に 対する耐候性鋼の腐食速度の抑制が確認された，以後 2 年目においても，同様の傾向が認められた。ここで，日 ごとの腐食速度を算出する際の精度を測定点のばらつき から算出すると $0.04 \mathrm{~mm} \cdot \mathrm{y}^{-1}$ 以下の腐食速度の領域では ばらつきの影響が大きく評価が難しい。この領域を評価 する場合には, 初期の $\mathrm{ER}$ センサ厚さを薄くして精度を 高めるなどの工夫が必要となる.

以上から，ER センサを用いることは耐候性鋼の腐食 挙動の詳細を評価できる可能があることが分かった。

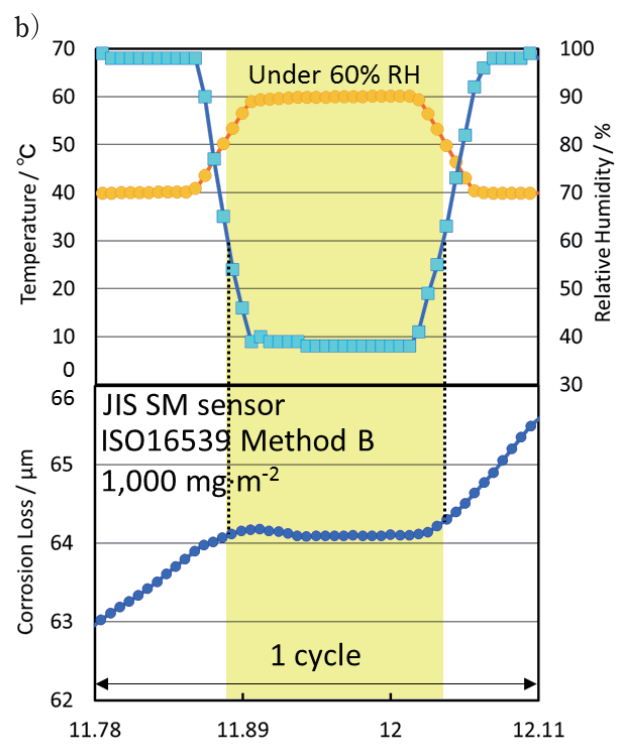

Fig. 7 Comparison of corrosion behavior in Okinawa exposure test site for JIS carbon steel /SM between a) in atmospheric environment and b) in ISO16539 Method B. 


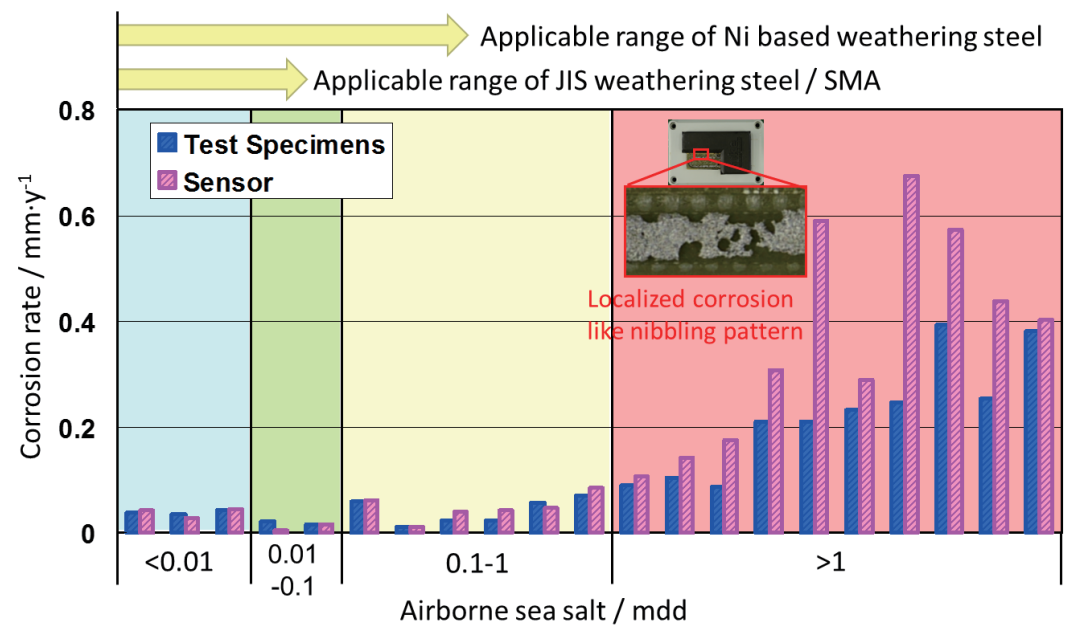

Fig. 8 Diffrence of corrosion rate between ER sensors and test specimens in each airborne sea salt range.
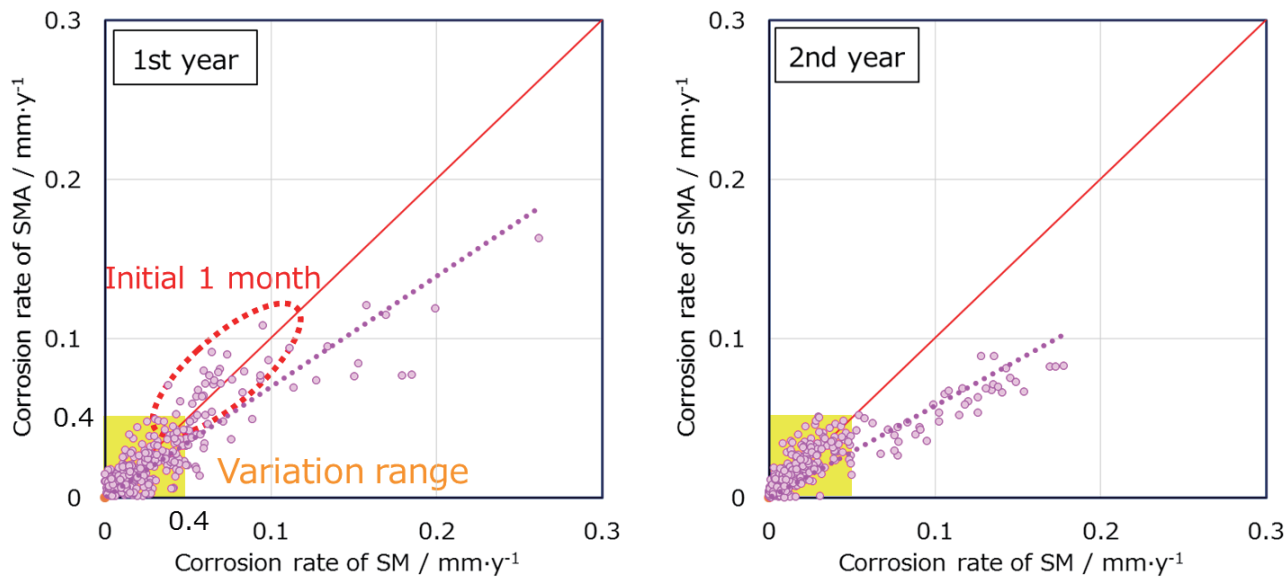

Fig. 9 Comparison of daily corrosion rate between JIS carbon steel / SM and JIS weathering steel / SMA in Kawasaki exposure test site.

\section{5. 結}

1）電気抵抗法により，耐候性鋼の腐食挙動の経時変化 を詳細に計測することが可能であった。

2）電気抵抗法を用いた場合，ERセンサ全体の抵抗を計 測する特性上，月平均の飛来塩分量が $1 \mathrm{mdd} \mathrm{NaCl}$ を 超えるような地域では，不均一腐食が生じ，試験片 腐食量と ER センサに乘離が生じる。しかし，上記 の飛来塩分量の領域は現行耐候性鋼の適用範囲外で ある。

3）普通鋼と腐食挙動および環境因子との比較により, 各種耐候性鋼が効果を発揮するまでの挙動や発揮可 能な環境を明確にできる可能性がある。

注：本文に掲載の商品の名称は各社が商標として使用 している場合があります。

\section{参 考 文 献}

1) Weathering steel bridge data collection book, 19th Edition, Japan Bridge Association Inc. (2012).

2) M. Omoda, H. Harada, H. Kajiyama, and M. Kimura, Zairyo-to-Kankyo, 65, p.274 (2016).

3) M.Omoda, H. Harada, T. Kawano, H. Kajiyama, and M. Kimura, Proc. Material and Environments 2014, JSCE, pp.149-152 (2014).

4) M.Omoda, H. Harada, T. Kawano, H. Kajiyama, and M. Kimura, Proc. 19th International Corrosion Council , TH13 (2014).

5) M. Omoda, D. Mizuno, and N. Ishikawa, Proc. PRiME2016, $1296(2016)$

6) ISO16539:2013, Corrosion of metals and alloys - Accelerated cyclic corrosion tests with exposure to synthetic ocean water salt-deposition process - "Dry" and "wet" conditions at constant absolute humidity.

7) T. Prosek, N. Le Bozec, and D. Thierry, Materials and Corrosion, 65, p.448 (2014).

8) JIS Z 2371:2000, Methods of salt spray testing.

9) I. Kage, K. Shiotani, M. Takemura, T. Komori, A. Furuta and K. Kyono, Zairyo-to-Kankyo, 55, p.152 (2006).

(Manuscript received January 23, 2018; in final form March 8, 2018) 
要 旨

耐候性鋼製の鋼構造物を保守・管理していく上で，日々変化する腐食環境と各種耐候性鋼の腐食挙動の 関係を把握することが重要となる。これには, 腐食量の経時変化を詳細に計測可能な腐食モニタリングす る技術が有効である。本研究において, 電気抵抗法を用いた腐食センサに耐候性鋼を使用し, 大気腐食試 験環境を模擬した耐食性試験法 ISO16539B 法と大気暴露環境で腐食モニタリングを行った。ラボ試験, 大 気暴露試験ともに $\mu \mathrm{m}$ 単位で各種耐候性鋼の腐食挙動差を明確に計測できた。一方で，大気暴露環境にお いて, 高塩分環境では, セン卅部に局所的な腐食が発生し，凹凸が大きくなることに起因した部分的な抵 抗值の上昇により, 出力される量が実際の腐食量よりも大きくなることを発見し, センサの適用可能環境 を飛来塩分量 $1 \mathrm{mdd}$ 以下と明確化した。このように, 電気抵抗法を用いることで, 各種耐候性鋼の腐食挙 動の差を計測でき, さらには, 腐食環境との比較により, 各種耐候性鋼が効果を発揮する環境条件を明確 化できる可能性を見出した.

キーワード＼cjkstart電気抵抗法，耐候性鋼，ISO16539 B 法，暴露試験 